\title{
A propósito de la Educación para la Ciudadanía Mundial. Una entrevista al profesor Carlos Alberto Torres
}

\author{
About the Global Citizenship Education. \\ An interview with Professor Carlos Alberto Torres
}

\section{Alícia Villar-Aguilés ${ }^{1}$}

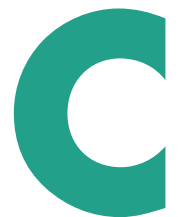

arlos Alberto Torres (Buenos Aires, 1950) es distinguished professor en la Universidad de California, Los Ángeles (UCLA), institución en la que fundó y dirige el Instituto Paulo Freire. Dirigió el Centro de Estudios de América Latina (1995-2005). En el período 2013-2016 presidió el Consejo Mundial de Sociedades de Educación Comparada y, actualmente, es director de la Cátedra UNESCO de Educación para la Ciudadanía Mundial. El interés por la obra de Freire lo llevó a fundar y dirigir el Instituto Paulo Freire de São Paulo (Brasil) y el de Buenos Aires (Argentina), dedicando una parte importante de su trabajo al pedagogo brasileño. Además, la actividad investigadora de Torres se ha desarrollado en el ámbito de la sociología política de la educación y el impacto de la globalización sobre la educación primaria y secundaria. Recientemente, en julio de 2019, ha coordinado la obra Wiley Handbook of Freire (editorial Wiley).

Alícia Villar-Aguilés entrevistó a Carlos Alberto Torres con motivo de su visita a la Universitat de València para impartir una conferencia en la Facultad de Ciencias Sociales titulada Educación para la Ciudadanía Mundialy los Derechos Humanos el 10 de diciembre de 2018, precisamente el mismo día que se cumplía el 70 aniversario de la proclamación de la Declaración Universal de los Derechos Humanos por parte de la Asamblea de Naciones Unidas. Esta entrevista ha sido publicada anteriormente en la Revista Futura de la Universitat de València en su versión en catalán. Ahora la publicamos en la $R A S E$ por su relevancia para reflexionar sobre algunos de los principales debates en el mundo de la educación. Esta reflexión enmarca la mirada sobre el Sur en relación con la dialéctica de lo local y lo global, cuestión a la que ha dedicado algunas de sus numerosas obras.

Este año se cumplen 50 años de Pedagogía del oprimido de Paulo Freire, una obra de la que usted es un gran conocedor, una obra referente y fundamental en las propuestas de transformación social y educativa. Quería preguntarle a propósito de este aniversario, ¿̇cómo de actual y necesaria se mantiene hoy en día la idea de una educación para la emancipación?

Creo que es el gran desafío de nuestro tiempo. La emancipación tiene que ser definida y, una vez que está definida, tiene que ser implementada. La definición de la emancipación ha cambiado con el correr de los tiempos y las luchas sociales y, actualmente, se podría decir que hay un vacío en la definición de la emancipación. Por ejemplo, lo que está pasando ahora en Francia, en referencia a las movilizaciones de los

1 Alícia Villar-Aguilés, Universitat de València: alicia.villar@uv.es. 
denominados «chalecos amarillos», puede ser considerada en parte como una lucha por la emancipación. Aunque no toda lucha refleja un modelo de emancipación. En el modelo de Freire la emancipación tiene que ver con la humanización, tiene que ver con la confrontación de las injusticias, de la dominación, de la explotación, de la opresión. Por eso, lo primero que destacaría es que hoy por hoy no hay un punto sinodal, es decir, algo central para definir qué es la emancipación, sino que tenemos un conjunto de modelos de emancipación. Hay otro elemento que podemos asociar a esta cuestión de la emancipación que es la emancipación ligada a confrontar el capitalismo. Es muy importante esa pregunta, porque el capitalismo tiene una ventaja y a su vez una desventaja. La ventaja es que el capitalismo crea riqueza. Pero por el otro lado, el capitalismo, lo que nunca ha podido hacer y probablemente nunca pueda hacer es distribuir la riqueza. Entonces, entre la creación de riqueza y la distribución de riqueza está la gran tensión que hoy por hoy se ha definido entre democracia y globalización. Por lo tanto, estos problemas requieren un modelo de estado lógico y humano y ese modelo tiene que ser democrático, pero a su vez tiene que ser multicultural y tiene que respetar los derechos humanos y los derechos de la naturaleza. Todos estos elementos son elementos de emancipación.

En su texto 'Mi última conversación con Paulo Freire', narra que, en aquel momento, en 1997, Freire y usted estaban iniciando la idea de un libro y Freire le respondió de manera lacónica «Tenemos que hacer una crítica al neoliberalismo. Es el nuevo demonio del mundo actual». Han pasado veinte años. ¿Cómo de lacónica sigue esa frase? Dije «lacónico» en el sentido de algo muy taxativo y muy inmediato, porque se cortó la comunicación. Pero yo creo que Freire, que era un hombre genial, hizo una observación importante. Freire era un pensador brillante anclado en el contexto del nordeste brasilero que estaba luchando para conocer y se da cuenta que la alfabetización es crucial como modelo de ciudadanía. En una de sus historias maravillosas cuenta le pidió a su cocinera hacer una prueba pidiéndole que le deletrease por sílabas la palabra ladrillo, que en portugués es «tijolo». Con la palabra ladrillo, Freire hará después alfabetización porque se convierte en elemento central en una comunidad que sobrevivía haciendo ladrillos, se trata de un elemento existencial. Esa manera de usar las palabras ligadas a la realidad más próxima. Freire era un gran observador de la realidad y estaba circunscrito al contexto. De ese contexto emerge con éxito su programa de alfabetización, y lo ponen a dirigir el programa de alfabetización nacional. Pasó de una experiencia hecha por una universidad, porque él era el director de extensión de una universidad, al reto de cambiar todo Brasil. Y eso significó que iba a transformar la construcción de la ciudadanía porque en Brasil solo votaban los que sabían leer y escribir o eran propietarios. Entonces, Freire lo que está diciendo con esa frase lacónica es que se estaba dando cuenta que el neoliberalismo era un enemigo de la humanidad, que era algo que deshumanizaba. Y yo me pongo a pensar, cuando Freire me dice esta frase, porque además fue la última vez que conversé con él, ya que murió a los pocos días después, que Freire estaba pensando en el neoliberalismo como diabólico y que la educación confronta el neoliberalismo, confronta la maldad en ese sentido de deshumanización. Y esto me ha hecho pensar mucho en otras cosas, por ejemplo, Hannah Arendt, la gran pensadora, y su idea de la banalidad de la maldad. La banalidad de la maldad es una perspectiva de gran actualidad en el panorama político internacional. Freire estaba confrontando la maldad, como Hannah Arendt. Nos estaba explicando que la maldad existe. El neoliberalismo es un modelo que está extrínsecamente vinculado al desconocimiento de las necesidades del otro y está en contra del estado de bienestar social porque la competencia es la solución a todos los problemas, mientras que los que no pueden competir tienen un problema muy serio y tienen que desaparecer. Lo que Freire estaba diciendo 
en definitiva con aquella frase es que el neoliberalismo es el nuevo demonio de nuestros días, porque no es capaz de tener compasión, no es capaz de tener solidaridad. Como he dicho, Freire era un gran observador de la realidad y la realidad que mejor conocía era la suya de origen, el nordeste de Brasil. Hay como una tradición nordestina de desesperanza. Freire quería cambiarla. Y la desesperanza que Freire quería cambiar no era preparar gente para que emigrara o para realizar trabajos muy precarios en grandes ciudades, sino impulsar el desarrollo en su zona. Era un desarrollista en cierto sentido, pero era un hombre que tenía las grandes preguntas fundamentales. Por eso, Freire tiene una epistemología muy lúcida, y su capacidad de inteligencia era su capacidad de observación.

Estaba leyendo hace poco un reciente artículo suyo publicado en la Revista Lusófona de Educação El estado del arte en educación comparada, que como usted sabe es una revista dirigida por el profesor António Teodoro. En ese artículo usted afirma que estamos inmersos en la actualidad en una crisis de humanidad. Me gustaría que detallara un poco más esa idea tan potente, esa afirmación tan rotunda y qué papel tendrían las políticas de educación ante esa crisis de humanidad.

En 1997, hacia el final de la vida de Freire, hubo en Brasilia una consulta con indígenas y vinieron jefes indígenas de todas las partes de Brasil. Uno de ellos se tenía que alojar en una casa a la que llegó muy tarde y estaba cerrada, así que se puso sus ropas y se acomodó fuera de la casa para pasar la noche. Pasaron unos jóvenes con un coche y lo vieron y le tiraron gasolina, le prendieron fuego y lo mataron. Cuando les preguntaron por qué lo hicieron, ellos contestaron que no sabían que era un jefe indio, sino que pensaban que era un mendigo. Este hecho destruyó psicológicamente a Freire. Alguna gente considera que este hecho fue uno de los actos donde Freire sucumbió, donde tiró la toalla. Le cuento esto a propósito de su pregunta sobre la crisis de la humanidad. Por otra parte, si uno conoce lo que le estaba pasando a Umberto Eco hacia el final de su vida fue similar en este sentido de descrédito, un hombre como él que había dado textos seminales en ciencia, el mejor semiólogo en Europa probablemente y autor de unos de las obras de literatura más apreciable, como El nombre de la rosa. Maravilloso, sin duda. Sin embardo, hacia el final de su vida dejó de creer en la vida y sus últimos comentarios son terribles. Yo espero no terminar así, aunque hay muchas razonas para creer que la humanidad se va a destruir a sí misma. Las crisis de la humanidad se dan cuando es imposible articular los intereses sociales y los intereses culturales con los intereses individuales en los contextos donde esa articulación tiene que tener lugar. Estamos pasando por un momento donde las naciones al interior de sí mismas y entre sí no están articulando intereses. Y esto genera conflictos. Podemos estar en el principio de una especie de tercera guerra mundial o, si no, digamos en el principio de la desarticulación del sistema internacional que previene esos conflictos que son las Naciones Unidas. En nuestras vidas a cierta edad pensamos que somos indestructibles, pero no es así porque el cuerpo poco a poco nos da pautas de que no lo somos. Las civilizaciones son indestructibles porque en última instancia -a menos que haya una catástrofe nuclear- van a seguir existiendo. La pregunta es cómo hacemos para crear un dialogo intercivilizacional que sea democrático y multicultural y que defienda esa democracia cosmopolita, pero una democracia cosmopolita que acepte el diálogo para ver las diferencias entre los conocimientos y entre los saberes.

Y en este sentido de crisis de humanidad en su relación con la educación, ¿̇qué papel tienen las políticas educativas ante esa crisis?

Eso es fundamental planteárselo. Voy a poner un ejemplo que parece simple, pero que nos puede hacer 
pensar sobre ello. Cuando en Estado Unidos vas a comprar una casa y le preguntas al agente inmobiliario ¿qué es lo más importante de una casa? Te dirá que location, location, location. Entonces, podemos trasladarlo al caso de la democracia preguntándonos, ¿qué es lo más importante para construir la democracia? Education, education, education. Es decir, la educación es un elemento absolutamente central en la construcción del sujeto individual, en la construcción de los sujetos colectivos y en la construcción de la ciudadanía. Sin embargo, la educación no podrá funcionar si no funciona la ley, y la ley se rompe todos los días. A mi entender, en la reconstrucción política -que es inminente y necesaria en los países en los que existe la democracia y donde la democracia está en peligro- hay que recrear el espacio jurídico, político-jurídico. Si la ley es una ley que va en contra de los derechos humanos hay que cambiarla; si la ley va en contra de la emancipación, hay que cambiarla. Tenemos muchas sociedades con democracias pobres y débiles: la democracia argentina, la brasilera, la mexicana, por citar algunas. Son democracias flacas: la democracia mexicana acosada por la violencia del narcotráfico; la democracia brasileira, acosada por las luchas intestinas al interior de los partidos y la corrupción; la democracia argentina, acosada por la corrupción, en parte por el narcotráfico, por la falta de diálogo entre los partidos políticos. Cada vez hay más países democráticos que no lo son, pero la democracia no está en decadencia. Está simplemente acosada por una realidad, y esa realidad viene de lo más profundo, de las partes oscuras del ser humano. Si la ley y la democracia no funciona, la educación no funcionará.

La Agenda para 2030 que marcó el Foro Mundial de Educación en 2015 persigue una educación en términos de equidad e inclusión, de calidad y aprendizaje a lo largo de toda la vida. $\dot{\partial}^{E n}$ qué momento se encuentra el trabajo y las acciones para alcanzar este reto tan sustancial, esta idea de una educación equitativa e inclusiva?

Pienso que hemos dado unos pasos trascendentales desde el año 2015 -que no son muchos años, realmente- yo he participado en reuniones en Corea, por ejemplo, uno de los países que más ha apoyado este modelo, donde se reunieron 28 expertos de 26 países de todos los continentes, que están cambiando el currículum de las escuelas. Me quedé atónito por las ideas de mucha de esa gente y por los avances que habían hecho en tres años. Eso es algo muy positivo, pero no todo es positivo. Porque Estados Unidos ha salido de la UNESCO y quiere salir de Naciones Unidas. Siendo un país tan poderoso pone mucho más dinero para sustentar la UNESCO y quiere que por ello lo respalden en sus decisiones, pero como son instituciones multilaterales el voto de un país menos poderoso que no paga tanto tiene el mismo peso. Estados Unidos no acepta eso. El hecho de que Estados Unidos haya tomado ciertas decisiones: el llevar la embajada de Estados Unidos a Jerusalén es un error histórico, geopolítico, tremendo, que va a crear una situación en Medio Oriente que no sé a dónde puede llegar. Y además, el hecho de que ahora Bolsonaro haya hecho la misma declaración en Brasi, son errores históricos de gobiernos que pueden afectar profundamente la construcción de la multilateralidad. Estamos en el momento de la crisis de la multilateralidad. En América Latina se sospecha de todo aquello que diga «global», como «educación global», porque se sospecha que sea una argucia de Estados Unidos para controlar y de manipular. Y esta sospecha se debe a que América Latina vive bajo la sombra de Estados Unidos. Pero Estados Unidos desde hace veinte años no tiene el menor interés en América Latina, sino que está preocupado por lo que pase en este momento en Asia, Europa y Medio Oriente. Y ahora con Trump, ya realmente, no le interesa mucho Europa tampoco. Considero que sin una multilateralidad eficiente, no hay democracia cosmopolita, y no funcionan los sistemas internacionales, y, por tanto, estas tensiones pueden poner en peligro la Agenda 2030 y el reto de la educación inclusiva. 
Hay una discusión internacional sobre la denominada epistemología del sur. Usted está trabajando sobre este tema.

Estamos ahora mismo en Europa, en una de mis ciudades predilectas en Europa, estoy con mis amigos en Valencia, con los cuales he compartido veinte años de sociabilidad, de trabajo político, de amistad, de comidas juntos, de trabajos académicos. Reconozco que incluso en lo que se llamó la provincialidad europea hay grandes argumentos anticoloniales, así como una diversidad política teórica en Europa que se aproxima y que busca fuentes mucho más allá de los clásicos, que son todos occidentales. Imaginar que se puede crear una nueva epistemología sin esos clásicos, imaginar que se puede considerar todo lo que viene de Europa como un epistemicidio, me parece una exageración que no lleva a ninguna parte. Claro que hay culturas que tienen pensamientos diferentes y que hay que rescatarlos y entrar en diálogo. Claro que hay posibilidades teóricas que no tienen nada que ver con las posibilidades teóricas occidentales pero eso no quiere decir que uno pierda de vista la riqueza de ciertas culturas analíticas porque hemos sido educados en esa riqueza.

Un autor que no voy a mencionar, lo mencionaré cuando haga un análisis más profundo, hace una lista de todas las dicotomías que surgen en los pensamientos occidentales y las listas son como 18 dicotomías, empezando por el bien y el mal. Y luego cuando hace la propuesta alternativa, crea su propia dicotomía. ¿A qué estamos jugando? Para tratar de confrontar todo eso a lo cual se le considera un epistemicicio, como una destrucción de las posturas epistemológicas de ciertos grupos y sabidurías, se crea una nueva dicotomía que a su vez es parte de una nueva epistemología. Ése es un juego perverso.

En la conferencia que nos ha dado hoy ha asistido un público muy joven de estudiantes de magisterio y usted ha mencionado que la generación de ahora es una generación educada en el neoliberalismo. El neoliberalismo mantiene continuamente un mensaje, explícita e implícitamente, de que el talento nos dará nuestro futuro, o que gracias a nuestros talentos podremos conseguir tal cosa o tal otra. Ese mensaje del modelo neoliberal se plasma en el modelo educativo meritocrático. Me gustaría preguntarle o simplemente compartir esta reflexión, ¿qué podemos decirles en este sentido a estos estudiantes de ahora que están formándose para ser los maestros y las maestras de un futuro ya muy cercano? ¿Cómo la emancipación -volviendo al término de la emancipación- casa con una educación neoliberal y con una educación en la que el mensaje meritocrático ha calado con tanta fuerza?

Muchas gracias por esta pregunta. El neoliberalismo como modelo económico ha fracasado completamente. Creo que la crisis de 2001, que luego se reflejó en la del 2008 en el mundo entero, es un ejemplo de lo que acabo de decir: ha fracasado. Sin un control del mercado, el mercado dejado a sus propias rutinas y dinamismos es un mercado salvaje. Y mire que yo creo que no podemos vivir sin mercados. El asunto es que no podemos tener esos mercados en un modelo de capitalismo salvaje. Pero, y esto es lo que yo he dicho muchas veces, alguna gente ya lo ha empezado a aceptar, la política de la cultura y la política de la educación que ha engendrado el neoliberalismo han sido excepcionalmente exitosas. Por tanto, lo que yo les dije a estos jóvenes hoy, es que ellos han sido educados en el individualismo posesivo, y el individualismo posesivo cuestiona todos los elementos y los regímenes de los derechos humanos, los regímenes de un estado que controla el capital, es decir, cuestiona todo lo que nos permite tener redes de solidaridad. Lo importante que quiero decir a estos jóvenes de hoy en día es que todo el mundo tiene talentos. Pero los 
talentos están por naturaleza diferencialmente distribuidos: hay gente que tiene talentos naturales y hay gente que tiene cuestiones adquiridas. Entre lo natural y lo adquirido corre la vida de nuestros días. No está nada mal hablar de que en la educación hay que promover talentos, es un modelo que creo que tiene sentido. Por eso les hablé de un ejemplo muy claro: desarrollen el talento de su escritura. Hay muchísimos ejemplos más. Ahora bien, si este modelo del cual estamos hablando es simplemente una certificación y esta certificación se obtiene a toda costa, esto no quiere decir promover talentos. Promueve cierto modelo de ascenso social, sí, pero no promueve talentos.

La meritocracia reducida en última instancia al credencialismo, a la emisión de certificados, puede generar el efecto perverso de ocasionar una compraventa de títulos, un fenómeno que está destapándose aquí últimamente, porque se han conocido casos de corrupción académica al descubrirse que se han otorgado títulos de másteres de manera fraudulenta.

Eso pasa en la política del mundo entero: una persona que aparece diciendo que estudió en la Wharton School y solo fue una semana y se presenta como graduada de la Wharton School. Es un mentiroso. Así no desarrollamos talentos. ¿Cómo deberían desarrollarse los talentos? Desarrollándose en un proceso donde el individuo aprende a desarrollar sus talentos individuales en colectividad. Ante eso el neoliberalismo está en contra, porque para el neoliberalismo todo lo que es colectivo es preocupante. Mi conclusión es simplemente ésta: el neoliberalismo usa todos los mecanismos, que tú denominaste «meritocráticos». La promoción de lo meritocrático, si realmente se promueven méritos no tiene ningún problema para mí, pero la promoción meritocrática de la cual estamos hablando son modelos formales cuyo impacto en la construcción social de la realidad es solamente para justificar y legitimar las diferencias, que ya existen en aquellos que acumulan los recursos sociales, políticos, económicos, y que ahora suman la certificación académica. 